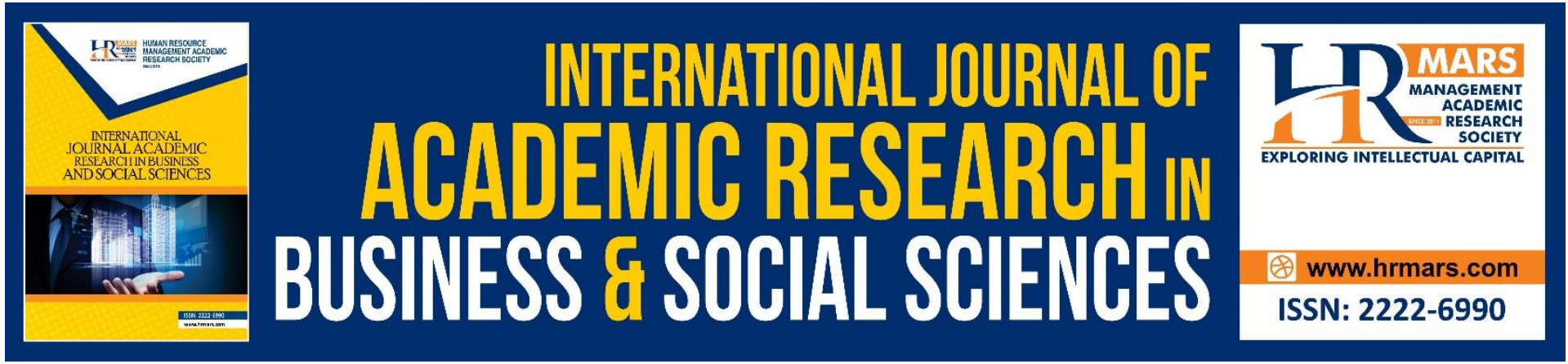

\title{
Theatre in Education: The Implementation of Improvisation in Dialogue Pronunciation Technique in Teaching
}

\section{Muhammad Faisal Ahmad, Zolkipli Abdullah, Abdul Walid Ali}

To Link this Article: http://dx.doi.org/10.6007/IJARBSS/v11-i8/10772

DOI:10.6007/IJARBSS/v11-i8/10772

Received: 20 June 2021, Revised: 22 July 2021, Accepted: 02 August 2021

Published Online: 19 August 2021

In-Text Citation: (Ahmad et al., 2021)

To Cite this Article: Ahmad, M. F., Abdullah, Z., \& Ali, A. W. (2021). Theatre in Education: The Implementation of Improvisation in Dialogue Pronunciation Technique in Teaching. International Journal of Academic Research in Business and Social Sciences, 11(8), 726-735.

\section{Copyright: @ 2021 The Author(s)}

Published by Human Resource Management Academic Research Society (www.hrmars.com)

This article is published under the Creative Commons Attribution (CC BY 4.0) license. Anyone may reproduce, distribute, translate and create derivative works of this article (for both commercial and non-commercial purposes), subject to full attribution to the original publication and authors. The full terms of this license may be seen at: http://creativecommons.org/licences/by/4.0/legalcode

Vol. 11, No. 8, 2021, Pg. 726 - 735

Full Terms \& Conditions of access and use can be found at http://hrmars.com/index.php/pages/detail/publication-ethics 


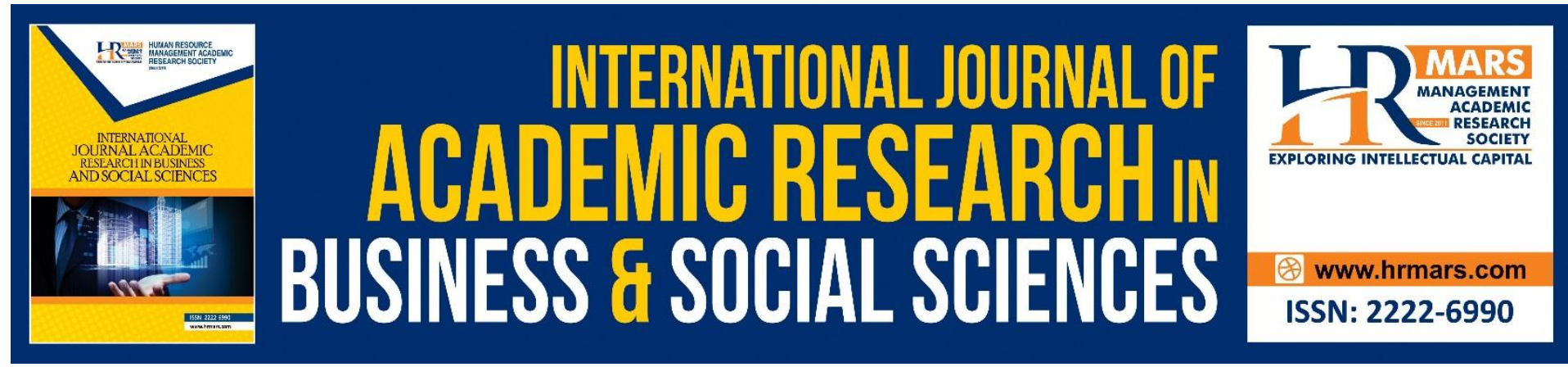

\title{
Theatre in Education: The Implementation of Improvisation in Dialogue Pronunciation Technique in Teaching
}

\author{
Muhammad Faisal Ahmad, Zolkipli Abdullah \\ Faculty of Music and Performing Arts, Sultan Idris Education University, Malaysia
}

\author{
Abdul Walid Ali \\ Faculty of Applied and Creative Arts, Universiti Malaysia Sarawak, Malaysia
}

\begin{abstract}
The improvisation in dialogue pronunciation will give significance based on the suitability of its application in teaching contexts. Copying, repetition, appreciation, action and reaction are the elements included in the techniques practised in acting. This study is fully dedicated to the implementation of dialogue pronunciation through improvisation technique which is often highlighted for the actors and actresses in acting. However, what goes unnoticed is the fact that the way a teacher delivers a lesson in a classroom has similarities in function and role as a stage performer. Voice is the main instrument which needs to be used during the whole lesson or performance. The problem statement in this study can be seen from the inability of the teacher to apply an effective dialogue projection technique in their lesson, causing a somber and gloomy classroom. Apart from that, understanding the teaching content alone is not enough if dialogue pronunciation is unclear throughout the lesson. Therefore, this study aims to give exposure on the techniques and introduction to voice mechanism so that the lesson can be delivered more effectively and interesting by the teachers. The process of this study leads towards qualitative form guided by observation and open interviews to review the current teaching methods as well as using suitable library and database references. The result of this study shows the importance of understanding the improvisation in dialogue pronunciation in teaching which can be implemented consciously in teaching and learning process in school.
\end{abstract}

Keywords: Theatre In Education, Improvisation, Dialogue Pronunciation, Teaching

\section{Introduction}

Dialogue pronunciation in acting is defined as conveying information or portraying a script in visual forms and it is one of the branches of pronunciation (Cooper, 1977). Aristotle had listed five important elements to form pronunciation deliverance which are the main idea, style or language used by the performer, improvising ideas and the ability of the performer to deliver the dialogue based solely on their memory (Dodd, 1973). In the context of stage play, dramatic pronunciation is when an actor delivers the dialogue directly from the stage. In 
western and developed countries, stage voice is the main requirement for an actor, since their voice needs to be directly heard by the audience without the aid of microphones and speakers. For voices that are assisted by microphones and speakers, it is considered as an ancient method. Proofs from the history of the development of the world dramatic arts show that actors acting without any aid is an old method from ages ago.

A high quality voice is not only evaluated from a good tone because there is no measurement on the level of evaluation for tones, agreeing that the factors influencing the evaluation are more subjective and they depend on certain individuals' opinion. Nevertheless, the effort to bring perfection in the techniques of dialogue pronunciation brings forth several studies that can be considered so that the performer can impact the audience or listeners. One of them is the determination to tell stories in front of an audience. Determination will trigger the spirit to convey an energetic play, facing any obstacle when delivering the dialogue and will go through maturity process stage by stage.

In the context of improvising dialogue pronunciation, according to Hodgson \& Richards (1967), improvisation means spontaneous reaction towards unexpected situations. Improvisation can be done based in situations, photographs, characters and clues. Improvisation in this context refers to non-linguistic element which is a no-voice technique and happens using body parts such as facial expression, body gestures and poses. Improvisation technique is a technique of spontaneous act, conducted by the actors themselves without referring to the script. This technique requires the actors to find new ideas based on the current one using their own creativity. Commonly, improvisation needs impeccable imagination and creativity. Even though improvisation technique can occur in various forms, this study focuses solely on action.

\section{Improvisation in Dialogue Pronunciation}

Improvisation is often implemented in education. This technique is used in teaching and learning in classrooms. Usually, interaction is an improvisation process that happens between students and teacher during a question and answer session or a spontaneous opinion. Improvisation is also often existed based on the simulations conducted by the teacher. In simulation, students are asked to create their own dialogue and act spontaneously. Simultaneously, this process tests on how competent is their mind and stimulus. Furthermore, creativity and imagination are also cultivated during this process. Sarason (2017) stated that:

'In essence, improvisation is quite simply a play without a script, because there is no need for a script, an improvised play does not depend on any form and skill or ability at reading, no on learning and remembering lines, and is thus an activity that all children of every age group and every scale of ability are able to both enjoy and master."

The relationship between improvisation and the shaping of acting is close. The use can motivate and stimulate an actor to connect their feelings with their characters through expressions in action and movement. Actions on stage, however spontaneous it is, needs to be relevant so that the storyline does not stray from its original idea. 
In the context of this study, improvisation also includes unconscious actions resulted from daily routines. These actions become a symbol, able to picture situations, feelings, emotions and others. For instance, body gestures like fisting hands to show anger, waving hands to bid goodbye, shrugging shoulders to tell that you don't know, putting a finger to the lips as an indicator to silence someone, and many others. Non-verbal gestures have become symbols understandable to everyone. However, there are body gestures that can only be understood by certain race, tribe or culture like Malay culture. For example, walking in front of the elderly by bending the body for a bit as a show of respect, shaking hands and putting the hand on the chest as appreciation and other gestures that cannot be understood by other cultures.

Gestures in general often involve unconscious body movements. This situation does not only happen accidentally, but it also brings different meanings to the listeners or audience. The symbols in movement that are understood sometimes will convey opposite meanings to the spoken statement. Asking 'Are you well?' while fisting the hands and cracking hand muscles will convey a negative meaning even though it is said with a calm tone and face. The same thing can also be applied when a 'Thank you' is said with the face facing another way and glaring which means nothing like the initial meaning. These situations are a symbol of improvisation to avoid cliches in acting. Stressing on the improvising act will bring more impact on acting since the audience needs to only interpret without long speeches.

\title{
The Implementation of Voice Mechanism in Teaching
}

The techniques in dialogue pronunciation put emphasis on languages, intonation, as well as correct and suitable pronunciation based on the background of the story (Nortier Simanungkalit., 2018). Some examples include a situation where someone is furious, or when a mother is giving advice to her children, and many more. In the process of forming a good pronunciation of dialogue in teaching, expression is also involved since it helps the teacher to practise in conjuring suitable speeches with their respective gestures or facial expressions. For instance, cheerful, grief, sad and other facial expressions. A teacher acts as a performer that can predict certain facial expressions and imagine how someone in that particular situation will act and say, especially in the classroom. To convey good facial expressions, continuous skill and practice needs to be done so that the character development can be seen more clearly. Griggs (2016) has written about applying voice expressions in teaching by mentioning:

\begin{abstract}
Any serious teacher is recommended to learn and master these voice expressions through training all his/her face muscles effectively and recording him/ herself. The speed of how you can display them effectively, is a direct indication of your talent. Only a professional observer (student) can judge your performance. Never be tricked into thinking yourself persuasive. Most people think they can do so but give ridiculous results.
\end{abstract}

The main difficulty for a teacher from the aspect of dialogue pronunciation is, not everyone possesses 'stage voice' which is the voice quality for stage play. This quality includes the dynamic, intonation, projection, emotion, as well as feelings and the ability to put various characters through voice alone. Morever, most people possess moderate voices - voices that are applicable in their daily lives. Ultimately, the lesson is considered as failed for not fulfilling the requirements as stated. As these are often mislooked, teachers are placed in schools but 
not based on the criteria of having the vocal like an actor, instead, they prioritised the knowledge and skills in their respective options. However, the personality of the teacher is still evaluated through psychometric tests and appearance during interview sessions. These situations do not contribute much to how they speak and teach in actual classrooms. Repetition in teaching can change the teacher's character based on their surrounding and normalcy in daily routine.

To apply a good dialogue pronunciation teachnique, vocal usage needs to be emphasised by teachers so they know the capability of their voices. It is also very closely-related to character development. Vocal techniques, as defined by Siti Hajar (2008) in her workshop Vocal Techniques in Stage Performance is, "The way of producing good and true voice, until it sounds clear, beautiful and high, suitable to the character". She has also stated that there are several aspects that need emphasis in obtaining good vocals such as articulation which is pronuncing each word clearly and correctly.

Correct breathing methods for teachers also contribute towards the production of good quality vocals in which these techniques are divided into three stages - chest breathing, stomach breathing, and diaphragm breathing. The difference between these techniques is the process of air support that enters the involved mechanisms. Knowledge on sound support, sound production, and word production mechanisms are the essentials for a good vocal.

\section{- Sound Support Mechanism}

Sound support mechanism is one of the main breathing systems before the sound is produced. It consists of lungs, the entire trachea that goes to the lungs, chest, ribcage, diaphragm and abdominal muscles. The muscles in the sound support mechanism act immediately to release continuous air.

While inhaling, diaphragm muscles and ribcage will expand while the empty spaces in the lungs will be filled with air in a short period of time. The process of exhaling which involves the muscles in the stomach, ribcage and chest will push the diaphragm opposite to the lower part of the lungs, supporting the release of air. Diaphragm muscles will contract but not slacking.

\section{- Sound Production Mechanism}

This mechanism happens when vocal sounds are produced during the exhale without restriction or obstacle. Vocal sounds are influenced by the tongue, mouth condition and the shape of the lips. Two parts are involved in this mechanism - movable parts that consist of larynx, vocal chords, the muscles around the neck, the back and the tip of the tongue, uvula, soft palate and the palate itself; and unmovable parts which are laringopharynx, nasal cavity skull cavity (Figure 1 ).

When the air is released through vocal chords, they will vibrate and produce sounds. If the upper and lower muscles in the vocal chords are in correct structure, the produced sound will be projected more freely. They are opened when we breathe and closed when we swallow something. 


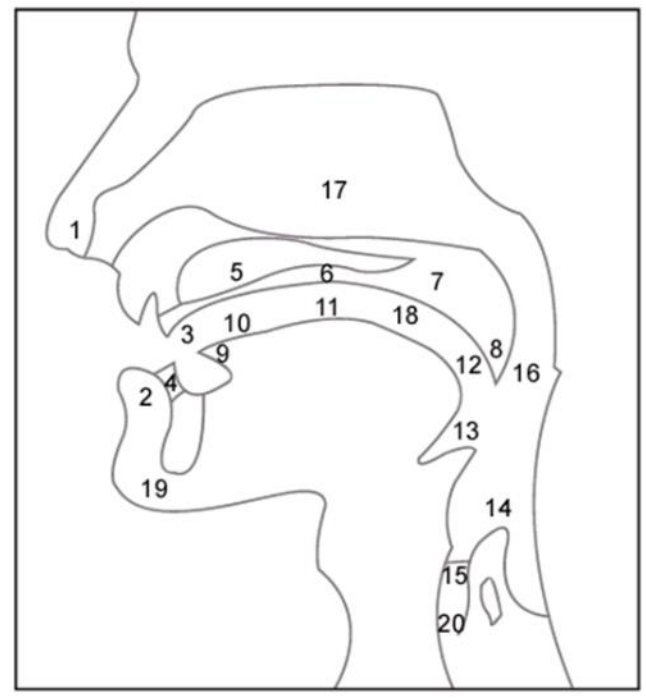

$\begin{array}{clll}1 & \text { Upper Lip } & 11 & \text { Middle of Tongue } \\ 2 & \text { Lower Lip } & 12 & \text { Back of Tongue } \\ 3 & \text { Upper Teeth } & 13 & \text { Root of Tongue } \\ 4 & \text { Lower Teeth } & 14 & \text { Epiglottis } \\ 5 & \text { Gum } & 15 & \text { Vocal Chord } \\ 6 & \text { Hard Palate } & 16 & \text { Pharynx } \\ 7 & \text { Soft Palate } & 17 & \text { Nasal Cavity } \\ 8 & \text { Uvula } & 18 & \text { Oral Cavity } \\ 9 & \text { Tip of Tongue } & 19 & \text { Jaw } \\ 10 & \text { Front of } & 20 & \text { Trachea } \\ & \text { Tongue } & & \end{array}$

Figure 1: Voice Mechanism

\section{- Word Formation Mechanism}

Word formation is a process that happens after sound is successfully produced by sound production mechanism. It is divided into lips, teeth, jaw, tip, front and middle parts of the tongue. These parts act to produce required vowel and consonant sounds. Sounds produced through vocal box will form words through the activities in oral cavity. Additionally, vowel and consonant sounds also follow jaw, lips, and tongue movements. In forming certain words, jaw, teeth and gums will play the main roles. It includes activities like chewing and swallowing which also involve word formation mechanism.

\section{Teacher's Character in Dialogue Deliverance}

Breathing mechanism has to support the voice from the direction of the lower part of the body. The ability of the voice that is supported needs to be taken care of and focuses on a particular part of the head. It has to be in a stable and consistent condition, not shaky, unchanged in quality nor dynamic escalation, except in responding towards the expressiveness in acting. A balance between inhalation and exhalation muscles will only occur if an actor had successfully implemented a good posture and breathing. This dynamic relationship referred to as breathing support is an important factor in assisting characterised voices (Withers-Wilson, 1995).

The moment a teacher applies dialogue pronunciation by supporting the tone in characters, imagination process is implemented as the produced voices in the classroom can be released freely from the body, but breathing is still controlled inside the body. In other words, breath will of course be released out of the body, but it needs to be controlled so it can be exhaled slowly. For instance, a teacher or an actor is inhaling deeply to shape an angry character, and this will help in slowing down the release of breath and preventing the expansion within the middle part of the body. The throat needs to feel free and open from the top to bottom. To obtain that feeling, the ability to maintain the initial position needs to be in the act of yawning. The palate has to feel like it's vibrating as if someone is speaking. This situation will influence the quality of the voice and the effectiveness of the voice box. 
Apart from going deep into the character created by the teacher, the effectiveness of said technique can also give quality towards the character through several basic aspects like variation, suitable dynamic and projection, delivering dialogues consistent to the character and emotions. Besides, it can also put energy in soft tones, giving various intonation to avoid monotonous sounds. In addition, putting the character not only on the facial expressions but on the voice identity itself can impact the audience from afar as they can still feel the emotions conveyed by the voice alone.

\section{- Dynamic Emphasis}

Dynamic emphasis is the emphasis on certain words in a dialogue. Harsh tones on particular words will give different emotion and meaning. It also functions to convey meaning and emotion leading towards voice intonation (Simanungkalit, 2008). A spoken sentence in teaching will give different impacts if the emphasis is put on different tones. For example:

\section{'Saya tidak suka makan NASI'}

- Dynamic is put on 'NASI' showing ultimate rejection towards rice. The emphasis is on the rice alone, not any other food.

\section{'Saya tidak suka MAKAN nasi'}

- Dynamic on the word 'MAKAN', showing full rejection on the act of eating. The dialogue is emphasised on eating, and not any other action.

\section{'Saya TIDAK SUKA makan nasi'}

- Dynamic in 'TIDAK SUKA', emphasising on the feeling of dislike. It puts focus on the feeling of dislike, not other emotions.

\section{'SAYA tidak suka makan nasi'}

- Dynamic on the word 'SAYA', emphasising on oneself. It refers to oneself, and not anyone else.

Based on the examples above, dynamic pressure impacts the meaning of emotions and thoughts. It is usually applied to convey opposition towards something. The emphasis on certain words will interpret the meaning of the spoken dialogue. In dynamic pressure, spoken dialogues do not necessarily give a one-time emphasis only. It can be in repetition or continuation, depending on the situation and emotions suitable to the scenes and characters. For instance:

'Aku BERJANI bahawa aku TIDAK akan membuat sebarang TUNTUTAN terhadap keputusan yang TELAH dibuat'.

Based on the example above, the dynamic is put on several words showing firmness through the words 'BERJANJI' and 'TIDAK'. Meanwhile, the emphasis on 'TUNTUAN' dan 'TELAH' refer to a firm action and do not refer to something that is not yet done. Therefore, it can influence the listeners and audience to support the sentence.

\section{- Tone Emphasis}

Tone emphasis commonly occurs when variation is put in dialogue intonation. Tone refers to the strength of high and low intonation in pronunciation. If the correct tone is not applied on 
the dialogue, it will surely be monotonous and boring. The significance of tone emphasis is to put meaning that contains different emotions. Some examples include expressing feelings or the probability of certain situations.

\section{'Benarkah dia telah mati? TIDAK!'}

- The tone on the word 'TIDAK' is increased drastically to express disbelief towards a known situation.

\section{'APA? Perjumpaan petang ini dibatalkan?'}

- The tone on 'APA' is in high volume to express the shock on the given information.

The emphasis on high tones is often applied to show dissatisfaction, shock, or expressing feelings with simple words without having to explan on the meaning. It is able to produce feelings that can be expressed by the listeners or audience. Emphasis can also happen in low tones even though the word is repeated like the example below:

\section{'Mengapa aku diperlakukan sebegini? MENGAPA?'}

- The word 'MENGAPA' is repeated but low tone is put on the repeated 'MENGAPA'. Different tones exhibit regret, sadness, and resignation.

\section{- Rhythm Emphasis}

Rhythm emphasis refers to the tempo or speed of the spoken dialogue. It is as important as the other emphasis. Rhythm contributes in beautifying a dialogue to give more effect towards the character and listener. It is also implemented to clarify thoughts so they can be easily understood and enjoyed the implicit meaning underneath the dialogues. Rhythm emphasis is more inclined to the 'colours' in dialogue deliverance. Although colours in this emphasis has the same function as explaining thoughts, the nature is stronger in providing great impact when used to express emotions and feelings.

\section{Conclusion}

Dialogue deliverance in teaching requires the teacher to know the elements in sentences. It is also related to the respiratory system so that long dialogues can still be uttered with correct rhythms. Other than that, the tempo needs to be clear so each word can be fully heard and understood. The variation in rhythm emphasis can be experimented according to the genre as long as it complies the message intended to be conveyed within the lesson. In teaching, togetherness is practised in assignment and activities, so every behaviour involving communication has to be considered as an interaction process in the classroom. This shows just how many different factors play a role in the relationship between a teacher and their students. In completing the elements that can be applied in body languages, improvisation in dialogues is often implemented to convey meanings without realising them. However, improvisation in pronunciation that are often conducted in teaching shows theatrical and non-theatrical gestures used in teaching and learning process; gestures formed from the desire to move suitable to the syllabus in the subject prior to the daily lesson plans. Thus, theatrical gestures applied in teaching are only created when the teacher is playing the role of a performer, as they themselves are performing in certain time and space. The improvisation in dialogue pronunciation in teaching also exhibits theatrical gestures applied through changes in facial expressions. In implementing this technique, culture is the element 
that plays a huge role in influencing non-verbal communication within a group in a society. This factor helps the improvisation to take root in acting if the performance is staged among local civilians who understand the body gestures. Therefore, it is clear that the role of a teacher is bigger than only focusing on their respective options. Mastering acting sciences especially in the aspect of improvisation in dialogue pronunciation will contribute to a more effective and enjoyable teaching and learning process.

In conclusion, the conceptual setting of acting methods such as the improvisation of dialogue pronunciation introduced by Stanislavski is apparently contributing to another field in developing teaching skills for teachers. The importance of effective delivery methods is not only seen through communication skills alone but is more inclined to a broader perception that is the response of the audience and listeners by communication. This knowledge of speech improvisation is a skill that needs to be explored by every people who holds the title of educator. Understanding each style and method of improvisation of speech for actors can help in creating another cross-disciplinary concept between performing arts and the field of education. This situation has proven that the field of acting also contributes greatly in shaping the personality, skills, and effectiveness in producing better quality human capital.

\section{Acknowledgement}

Deep appreciation and gratification for Faculty of Music and Performing Arts, Sultan Idris Education University (UPSI), Universiti Malaysia Sarawak (UNIMAS) and several individuals involved in data contribution throughout the in completing this research.

\section{Corresponding Authors}

Muhammad Faisal bin Ahmad

Faculty of Music and Performing Arts Sultan Idris Education University 35900 Tanjong

Malim, Perak, Malaysia

Email: mfaisal@fmsp.upsi.edu.my

\section{References}

Amatembun, N. A. (1989). Manajemen Kelas, Penuntun Bagi Guru dan Calon Guru. Bandung, FIP IKIP Bandung.

Bakar, A. A. (1981). Memahami Psikologi Pembelajaran. Kuala Lumpur: Fajar Bakti.

Benedetti, R. L. (1970). The Actor At Work. London: Prentice-Hall International.

Boal, A. (1979). Theatre of the Oppressed. London: Pluto Press.

Bochner, D. A. (2010). Discipline for Acting Out Students. Stephenson Avenue, Ste B Savannah, GA

Bogart, A. (2001). A Director Prepares: Seven Essays on Art and Theatre. London: Routledge.

Boleslavsky, R. (1987). Acting: The First Six Lessons (Theatre Arts Book). Routledge Theatre Arts.

Book, S. (2003). Book on Acting: Improvisation Technique for the Professional Actor in Film, Theater, \& Television. Silman-James Press.

Cooper, J. M. (1977). Classroom Teaching Skills. A Handbook. Lexingtong

Dodd, N. (1973). Drama and Theatre in Education. London: Heinemann Edcational Books.

Griggs, T. (2016). Teaching as Acting. New York: Teachers College Press

Hajar, S. (2008). Teknik Vokal dalam Persembahan Pentas. Seminar Pemantapan Koir Jabatan Perkhidmatan Awam, Pahang. 
Hodgson, J., \& Richards, E. (1967). Improvisation. London: Eyre Methuen.

James, R. A. (2007). The Art of Voice Acting: The Craft And Business of Performing for Voiceover. Focal Press, Taylor \& Francis, Inc.

Mohamad, B., \& Hashim, E. (2010). Gaya Pengajaran \& Pembelajaran. PTS Publishing Sdn. Bhd.

Mulyana, D. (1995). Pengantar Ilmu Komunikasi. Universitas Padjadjaran, Indonesia.

Sang, M. S. (2009). Teks Komprehensif PTK Bahagian II: Kursus/Fungsional Pengajaran \& Pembelajaran (P\&P). Penerbitan Multimedia Sdn. Bhd., Kuala Lumpur.

Sarason, S. (2017). Teaching As A Performing Art. Teachers College Press, New York.

Simanungkalit, N. (2018). Teknik Vokal Paduan Suara. Gramedia Pustaka Utama, Indonesia.

Suherjanto, I. (1997). Komunikasi dalam Seni Pertunjukan Teater. Kuala Lumpur: Longman Malaysia. 